\section{(6) OPEN ACCESS}

\title{
Risk of congenital anomalies in relation to the uptake of trihalomethane from drinking water during pregnancy
}

\author{
Regina Grazuleviciene, ${ }^{1}$ Violeta Kapustinskiene, ${ }^{1,2}$ Jone Vencloviene, ${ }^{1}$ \\ Jurate Buinauskiene, ${ }^{3}$ Mark J Nieuwenhuijsen ${ }^{4,5,6}$
}

\begin{abstract}
${ }^{1}$ Department of Environmental Sciences, Vytautas Magnus University, Kaunas, Lithuania ${ }^{2}$ Institute of Cardiology, Lithuanian University of Health Sciences, Kaunas, Lithuania ${ }^{3}$ Clinic of Obstetrics and Gynaecology, Lithuanian University of Health Sciences, Kaunas, Lithuania ${ }^{4}$ Center for Research in Environmental Epidemiology (CREAL), Parc de Recerca Biomedica de Barcelona (PRBB), Barcelona, Spain ${ }^{5}$ Municipal Institute of Medical Research (IMIM-Hospital del Mar), Barcelona, Spain ${ }^{6}$ CIBER Epidemiologia y Salud Pública (CIBERESP) Madrid, Spain
\end{abstract}

\section{Correspondence to} Professor Regina

Grazuleviciene, Department of Environmental Sciences, Faculty of Natural Sciences, Vytauto Didžiojo universitetas, Str. Donelaicio 58, Kaunas 44248, Lithuania; r.grazuleviciene@ gmf.vdu.It

Received 2 August 2012 Revised 14 January 2013 Accepted 16 January 2013 Published Online First 12 February 2013

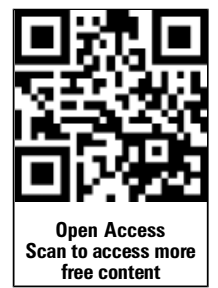

To cite: Grazuleviciene $\mathrm{R}$, Kapustinskiene $\mathrm{V}$, Vencloviene J, et al. Occup Environ Med 2013;70:274282.

\section{ABSTRACT \\ Objectives Congenital anomalies have been} inconsistently associated with maternal crude estimated exposure to drinking water trihalomethane (THM). We investigated the relationship between individual THM uptake during the first trimester of pregnancy and congenital anomalies.

Methods We estimated maternal THM uptake for 3074 live births using residential tap water concentrations, drinking water ingestion, showering and bathing, and uptake factors of THM in the blood. Multiple logistic regression was used to investigate the association of THM exposure with congenital anomalies. Results We observed no statistically significant relationships between congenital anomalies and the total THM internal dose. We found little indication of a doseresponse relationship for brominated THM and congenital heart anomalies. The relationship was statistically significant for bromodichloromethane (BDCM) $(\mathrm{OR}=2.16,95 \% \mathrm{Cl} 1.05$ to 4.46 , highest vs lowest tertile) during the first month of pregnancy. During the first trimester of pregnancy, the probability of developing heart anomalies increased for every $0.1 \mu \mathrm{g} / \mathrm{d}$ increase in the BDCM and for every $0.01 \mu \mathrm{g} / \mathrm{d}$ increase in the internal dibromochloromethane (DBCM) dose (OR 1.70, $95 \% \mathrm{Cl} 1.09$ to 2.66 , and OR $1.25,95 \% \mathrm{Cl} 1.01$ to 1.54 , respectively). A dose-response relationship was evident for musculoskeletal anomalies and DBCM exposure during the first and second months of pregnancy, while BDCM exposure tended to increase the risk of urogenital anomalies.

Conclusions This study shows some evidence for an association between the internal dose of THM and the risk of congenital anomalies. In particular, increased prenatal exposure to brominated THM might increase the risk of congenital heart and musculoskeletal anomalies.

\section{INTRODUCTION}

Epidemiological studies have suggested that pregnant women exposed to water disinfection by-products (DBPs) containing elevated trihalomethane (THM) concentrations may be at greater risk for adverse pregnancy outcomes, including fetal growth and congenital anomalies, characterised by structural deformities. However, findings of the studies completed to date have been inconsistent. ${ }^{1-4}$ The imprecision of exposure classification arising from the use of aggregate municipal measures is a major limitation of the prior studies. Most of the previous research has focused on total

\section{What this paper adds}

- There is growing, but inconsistent, evidence from epidemiological studies that maternal exposure to increased drinking water chlorination by-products, specifically trihalomethane (THM), may be associated with congenital anomalies.

- The majority of epidemiological studies use the THM concentration in drinking water as an index of exposure, rather than assessing THM uptake based on individual water consumption habits.

- Based on detailed, individual data on THM uptake in this cohort study of pregnant women, there is evidence that maternal exposure to brominated THM increases the risk of congenital heart and musculoskeletal anomalies, independent of other maternal characteristics.

exposure to THM. The relationship between DBP exposure and reproductive health outcomes remains unclear, primarily because of the crude exposure assessment in most studies. ${ }^{4-8}$

A recent meta-analysis of congenital anomalies studies indicated that exposure to DBPs may increase the risk of birth defects in general, especially neural tube defects, ${ }^{9}{ }^{10}$ urinary tract defects $^{2}{ }^{6}$ and respiratory defects. ${ }^{11}$ Some studies did not find such associations. ${ }^{12}{ }^{13}$ A few studies provided evidence of an elevated risk of cardiac defects, ${ }^{11} 1415$ while the results for neural tube defects and oral cleft defects were inconsistent. ${ }^{13} 15$ Crude exposure assessment limited the ability of most of these studies to assess dose-response relationships. In a cross-sectional study of the Norwegian population, the risks of ventricular septal defects, oral cleft defects, and obstructive urinary tract defects were related to DBP exposure. $^{11} \mathrm{~A}$ recent study in England and Wales reported significant excess risks of ventricular septal defects in the high-exposure categories of total THM (TTHM) $(1.43$; 95\% CI 1.00 to 2.04$)$ and of major cardiovascular defects and gastroschisis for bromoform $(1.18 ; 95 \%$ CI 1.00 to 1.39 and $1.38 ; 95 \%$ CI 1.00 to 1.92 , respectively). ${ }^{16}$ 
Because the prior studies did not include information on individual patterns of water consumption, showering or bathing, the assigned category of THM exposure may not accurately reflect actual THM uptake. Moreover, the studies varied in their ability to control for maternal characteristics that could also be associated with adverse pregnancy outcomes. These limitations make it difficult to compare results among the studies and to generalise the results to other populations.

We previously reported dose-response relationships for internal THM and chloroform $(\mathrm{CH})$ dose, over the duration of pregnancy and by trimester, with low birth weight and reduction in birth weight. ${ }^{17}$ To estimate exposure to THM at an individual level, we assessed different routes of THM uptake in a cohort of pregnant women in Kaunas.

In this epidemiological study, we used prospective data from a cohort of pregnant women to quantify individual THM uptake during pregnancy and to assess the effect of the internal THM dose on the risk of major congenital anomalies at birth. We adjusted our analyses for many potential risk factors for congenital anomalies. This is the first epidemiological study to evaluate the impact of individuals' internal THM dose on congenital anomalies.

\section{METHODS}

\section{Participant characteristics}

A prospective cohort study of pregnant women was conducted between 2007 and 2009 in Kaunas, Lithuania (Kaunas HiWATE cohort study). Details of the methods have been published elsewhere. ${ }^{17}$ We designed a questionnaire to collect individual information on the source and amount of drinking water, frequency of showering and bathing, residence duration and health characteristics. This water consumption and water use habits questionnaire was used to interview 3341 women who agreed to participate in the study, $76 \%$ of whom were interviewed during the third trimester of their pregnancy, and $24 \%$ by telephone within the first month after delivery.

Pregnancy outcomes were abstracted from medical records. Congenital anomalies, including both structural defects and functional abnormalities, were detected and diagnosed through routine medical procedures in the delivery unit. Estimates of gestational age based on the date of the mother's last menstrual period were validated by ultrasound. High-resolution ultrasound examination at three points during pregnancy was used to track fetal development. When a fetus was suspected of having an anomaly, the mother was referred for the appropriate specialised tests and examinations. To be included in this analysis, a congenital anomaly had to be definitively diagnosed after a live birth; probable anomalies, stillbirths, and terminations were excluded.

Congenital anomalies also had to be diagnosed before the infant was discharged from the hospital.

We obtained registry-based data on congenital anomalies in live infants, which were coded using the International Classification of Diseases (ICD) 10th revision. Consistent with other studies, congenital anomalies were combined into groups, including all circulatory system (heart) (ICD-10 codes Q20Q24, $\mathrm{n}=57$ ), musculoskeletal (ICD-10 codes Q65-79, $\mathrm{n}=37$ ), and urogenital (ICD-10 codes Q50-64, $\mathrm{n}=23$ ) anomalies. Other types of congenital anomalies were not included because of the small number of cases. Of the cases with congenital anomalies included in this study, 95.7\% had a single anomaly and $4.3 \%$ had multiple anomalies. The final analysis included 3074 women.
The reference group was defined as all live births without any congenital anomaly. We used questionnaires to gather information on potential risk factors for congenital anomalies, including maternal age, ethnicity, education, parity and smoking, among others.

\section{THM exposure assessment}

Drinking water for Kaunas is supplied by four water treatment plants, all of which use groundwater sources. Each plant supplies water to users after a single treatment (ie, one chlorination with sodium hypochlorite). Over the 3-year study period (2007-2009), quarterly tap water samples were collected in the morning from three sites per treatment plant: close to the plant, and at $5 \mathrm{~km}$ and $10 \mathrm{~km}$ or more from the plant. A total of 85 water samples were collected from 12 monitoring sites in four water supply zones for THM analysis. Water samples were analysed using gas chromatography with electron capture detection $^{18}$ and were conducted at the University of the Aegean, Greece. Measurements included specific values for each of the four regulated THM: $\mathrm{CH}$, bromodichloromethane (BDCM), dibromochloromethane (DBCM) and bromoform and nine haloacetic acids (HAAs). The nine HAAs included five haloacetonitriles, two haloketones, chloropicrin and chloral hydrate. In addition, selected samples were analysed at the National Institute for Health and Welfare (THM), Finland, for the halogenated furanone (MX). Only THM data were evaluated in this study because the other halogenated DBPs were undetectable or present only at low or sub- $\mu \mathrm{g} / \mathrm{l}$ levels.

We calculated the mean THM constituent concentrations for each of the three sampling sites per treatment plant. Depending on the TTHM levels at each plant water supply zone, we assigned a value of 'low level' (mean $1.33 \mu \mathrm{g} / \mathrm{l}$ ) and 'high level' zone (mean $21.9 \mu \mathrm{g} / \mathrm{l}, 54.9 \%$ subjects). We assigned a value to each woman based on the sampling site closest to her geocoded address at delivery.

Next, we estimated total exposure by applying the THM concentrations and water usage. Water usage was defined as ingestion, showering and bathing. We used uptake factors of 0.001536 and 0.001321 of THM in blood per minute per microgram from showering and bathing, respectively, to calculate daily internal dose. ${ }^{19} 20$ We also accounted for possible modification of uptake in micrograms per day $(\mu \mathrm{g} / \mathrm{d})$ by heating. $^{21} 22$ Details of these THM exposure assessment methods have been published elsewhere. ${ }^{17}$

We used average daily TTHM uptake $(\mu \mathrm{g} / \mathrm{d})$ in our analysis as a continuous and a categorised variable. Using a statistical computer programme, we calculated tertiles of the THM internal dose for the first trimester of pregnancy. This approach gave the low $(0.003-0.040 \mu \mathrm{g} / \mathrm{d})$, medium $(0.040-0.356 \mu \mathrm{g} / \mathrm{d})$, and high $(0.356-2.448 \mu \mathrm{g} / \mathrm{d})$ tertiles for the average TTHM uptake for the study of congenital anomalies. Then, to study heart, musculoskeletal and urogenital anomalies, THM uptake was determined for the first, second and third months of pregnancy. To reduce THM exposure misclassification errors, we restricted the analysis to the subset of women who had not changed their address throughout the entire pregnancy.

\section{Statistical analysis}

We first examined the risk of the three most common specific defects (heart, musculoskeletal and urogenital) in the 'high level' and 'low level' THM sites without accounting for water usage habits. Next, we assessed the congenital anomalies adjusted ORs for THM in DBP exposure categories based on the levels of TTHM representing high (TTHM $21.9 \mu \mathrm{g} / \mathrm{l})$ and 
low (TTHM $1.3 \mu \mathrm{g} / \mathrm{l}$ ) levels as the reference category. Then, the data analysis compared the heart, musculoskeletal and urogenital anomalies of low, medium and high exposed women to the total internal dose $(\mu \mathrm{g} / \mathrm{d})$ of THM and the specific THM constituents estimated as total uptake from drinking, showering and bathing. We used stratified $\chi^{2}$ a univariate logistic regression analyses to evaluate the associations among the covariates that are known to be related to increased risk of congenital anomalies. All covariates significantly associated with congenital anomalies, or that changed the adjusted ORs by $10 \%$ or more, were retained for inclusion in multiple logistic regression analyses.

After adjusting for potential confounders and congenital anomalies risk factors, we calculated ORs and 95\% CIs for the relationships between individual THM constituents and congenital anomalies. We also used the internal TTHM dose as a continuous variable in multiple logistic regression models to evaluate the relationship, if any, between congenital anomalies and every $1.0 \mu \mathrm{g} / \mathrm{d}$ increase in TTHM and $\mathrm{CH}, 0.1 \mu \mathrm{g} / \mathrm{d}$ increases in BDCM and $0.01 \mu \mathrm{g} / \mathrm{d}$ in DBCM internal dose. Analyses of congenital heart anomalies were adjusted for age, body mass index, chronic disease, alcohol consumption and fetus number. Analyses of musculoskeletal anomalies were adjusted for body mass index, fetus number, previous premature birth and infant sex. Analyses of urogenital anomalies were adjusted for age, body mass index, chronic disease, previous premature birth and infant sex.

\section{RESULTS \\ THM concentration}

The mean tap water TTHM level in the low-level site from three water treatment plants was $1.3 \mu \mathrm{g} / \mathrm{l}, \mathrm{CH}$ was $0.9 \mu \mathrm{g} / \mathrm{l}$, BDCM was $0.3 \mu \mathrm{g} / \mathrm{l}$, and DBCM was $0.1 \mu \mathrm{g} / \mathrm{l}$. The corresponding levels at the highest level site (Petrasiunai) were 21.9, 17.7, 3.6 , and $0.5 \mu \mathrm{g} / \mathrm{l}$, respectively. Bromoform was below the limit of detection at all sites. There was low seasonal variation in the THM levels measured at the sites and little spatial and temporal variability between the high and low sites. Although there was a difference in the TTHM concentration between Petrasiunai and the other sites, there was no difference in the levels of the other halogenated DBPs, which were undetectable or present at low or sub $\mu \mathrm{g} / \mathrm{l}$ levels. The mean levels (and SDs) of the dihalogenated and trihalogenated HAAs for Petrasiunai were $0.5(0.7)$ and $0.3(0.7) \mu \mathrm{g} / \mathrm{l}$, respectively, whereas they were $0.3(0.8)$ and $0.1(0.2) \mu \mathrm{g} / \mathrm{l}$, respectively, for the other sites combined. All the mean values for the other individual halogenated DBPs (ie, haloacetonitriles, haloketones, chloropicrin, chloral hydrate and monohalogenated HAAs) were less than $1.0 \mu \mathrm{g} / \mathrm{l}$ each for Petrasiunai and the other sites. Thus, because only THM levels were substantially different between Petrasiunai and the other sites, only THM data were included in this analysis. The correlation between individual THM concentrations was high $(r=0.91-0.99, p<0.05)$, as were the correlations between each month of the first trimester $(\mathrm{r}=0.88-0.96, \mathrm{p}<0.05)$. These correlations are the result of limited variability in the amount of THM produced at these groundwater treatment plants.

We found little evidence of a relationship between the TTHM concentrations in the maternal residential water supply during the first trimester of pregnancy and the risk of congenital anomalies (table 1). Crude (unadjusted) and adjusted analyses showed similar risk estimates. In multivariate logistic regression analyses, the adjusted ORs of congenital heart anomalies (OR $1.54,95 \%$ CI 0.89 to 2.68 ) and urogenital anomalies (OR 3.01, 95\% CI 1.11 to 8.16 ) were elevated in the high versus low TTHM level sites.

\section{Daily THM uptake}

The total estimated individual uptake of TTHM during the first trimester of pregnancy ranged between 0.003 and $2.448 \mathrm{mg} / \mathrm{d}$. The total $\mathrm{CH}$ uptake ranged between 0.001 and $2.109 \mathrm{mg} / \mathrm{d}$. In general, mothers supplied with water with a higher $\mathrm{CH}$ concentration generally had a higher total internal dose. Daily uptake of BDCM ranged between 0.000 and $0.436 \mathrm{mg} / \mathrm{d}$, and DBCM ranged between 0.000 and $0.093 \mathrm{mg} / \mathrm{d}$. Bromoform was below the limit of detection.

\section{Congenital anomalies risk factors}

Table 2 shows the percent distribution of congenital anomalies by maternal characteristics. The women who participated in the study were predominantly Lithuanian in ethnic origin $(97.5 \%)$ and did not smoke (93.4\%). Their mean age was 28.4 years, and the women tended to be highly educated $(44.7 \%$ with a university degree). In general, any congenital anomaly was more common in the babies of mothers with one or more of the following characteristics: not married, underweight or normal weight, second or over infant and previous preterm delivery.

There was no difference in the proportion of women who did and did not use water filters. The proportion of heart and urogenital anomalies cases tended to be higher among women with

Table 1 Crude and adjusted ORs and 95\% Cls for congenital anomalies by exposure to TTHM levels ( $\mu$ g/l) during the first trimester of pregnancy

\begin{tabular}{|c|c|c|c|c|c|c|}
\hline Total trihalomethane exposure $(\mu \mathrm{g} / \mathrm{l})$ & Cases n (\%) & Controls n (\%) & Crude OR & $95 \% \mathrm{Cl}$ & Adjusted OR & $95 \% \mathrm{Cl}$ \\
\hline \multicolumn{7}{|l|}{ Heart anomalies } \\
\hline Low $(1.3 \mu \mathrm{g} / \mathrm{l})$ & $20(35.1)$ & $1325(45.6)$ & 1 & & 1 & \\
\hline High $(21.9 \mu g / l)$ & $37(64.9)$ & $1578(54.4)$ & 1.55 & 0.89 to 2.69 & $1.54^{*}$ & 0.89 to 2.68 \\
\hline \multicolumn{7}{|l|}{ Musculoskeletal anomalies } \\
\hline Low $(1.3 \mu \mathrm{g} / \mathrm{l})$ & $19(51.4)$ & $1325(45.6)$ & 1 & & 1 & \\
\hline High $(21.9 \mu \mathrm{g} / \mathrm{l})$ & $18(48.6)$ & $1578(54.4)$ & 0.80 & 0.42 to 1.52 & $0.74 \dagger$ & 0.39 to 1.42 \\
\hline \multicolumn{7}{|l|}{ Urogenital anomalies } \\
\hline Low $(1.3 \mu \mathrm{g} / \mathrm{l})$ & $5(21.7)$ & 1325 (45.6) & 1 & & 1 & \\
\hline High $(21.9 \mu \mathrm{g} / \mathrm{l})$ & $18(78.3)$ & 1578 (54.4) & 3.02 & 1.12 to 8.16 & $3.01 \neq$ & 1.11 to 8.16 \\
\hline
\end{tabular}


Table 2 Percent distribution of congenital anomalies by maternal characteristics and $p$ value of $\chi^{2}$

\begin{tabular}{|c|c|c|c|c|c|}
\hline Risk factors & $\begin{array}{l}\text { Non-anomaly } \\
\mathrm{n}(\%)\end{array}$ & $\begin{array}{l}\text { Any anomaly } \\
\mathrm{n}(\%)\end{array}$ & $\begin{array}{l}\text { Heart } \\
n(\%)\end{array}$ & $\begin{array}{l}\text { Musculoskeletal } \\
\text { n (\%) }\end{array}$ & $\begin{array}{l}\text { Urogenital } \\
\mathrm{n}(\%)\end{array}$ \\
\hline \multicolumn{6}{|l|}{ Maternal age } \\
\hline$<30$ years & $1887(65.0)$ & $103(60.2)$ & $31(54.4)^{*}$ & $24(64.9)$ & $13(56.5)$ \\
\hline$\geq 30$ years & $1016(35.0)$ & $68(39.8)$ & $26(45.6)$ & $13(35.1)$ & $10(43.5)$ \\
\hline \multicolumn{6}{|l|}{ Marital status } \\
\hline Married & $2425(83.5)$ & $129(75.4)^{* *}$ & $46(80.7)$ & $28(75.7)$ & $20(87.0)$ \\
\hline Not married & $478(16.5)$ & $42(24.6)$ & $11(19.3)$ & $9(24.3)$ & $3(13.0)$ \\
\hline \multicolumn{6}{|l|}{ Maternal active smoking } \\
\hline Non-smoker & 2712(93.4) & $162(94.7)$ & $53(93.0)$ & $37(100.0)$ & $21(91.3)$ \\
\hline Smoker & $191(6.6)$ & $9(5.3)$ & $4(7.0)$ & 0 & $2(8.7)$ \\
\hline \multicolumn{6}{|l|}{ Passive smoking } \\
\hline Non-smoker & $1582(55.0)$ & $82(48.8)$ & $28(50.9)$ & $14(37.8)^{* *}$ & $13(56.5)$ \\
\hline Smoker & $1292(45.0)$ & $86(51.2)$ & $27(49.1)$ & $23(62.2)$ & $10(43.5)$ \\
\hline \multicolumn{6}{|l|}{ Alcohol consumption during pregnancy } \\
\hline No & $2724(93.8)$ & $165(96.5)$ & $56(98.2)$ & $35(94.6)$ & $23(100.0)$ \\
\hline Yes & $179(6.2)$ & $6(3.5)$ & $1(1.8)$ & $2(5.4)$ & 0 \\
\hline \multicolumn{6}{|l|}{ Ethnic group } \\
\hline Lithuanian & $2829(97.5)$ & $168(98.2)$ & $56(98.1)$ & $36(97.3)$ & $23(100)$ \\
\hline Other & $74(2.5)$ & $3(1.8)$ & $1(1.8)$ & $1(2.7)$ & 0 \\
\hline \multicolumn{6}{|l|}{ Maternal education } \\
\hline Primary school & $138(4.8)$ & $9(5.3)$ & $4(7.0)$ & $3(8.1)$ & $1(4.3)$ \\
\hline Secondary school & $1160(40.0)$ & $57(33.3)$ & $20(35.1)$ & $12(32.4)$ & $8(34.8)$ \\
\hline University degree & $1605(55.3)$ & $105(61.4)$ & $33(57.9)$ & $22(59.5)$ & $14(60.9)$ \\
\hline \multicolumn{6}{|l|}{ Parity } \\
\hline No child & $1429(49.2)$ & $86(50.3)$ & $24(42.1)$ & $22(59.5)$ & $12(52.2)$ \\
\hline$\geq 1$ child & $1474(50.8)$ & 85 (49.7) & $33(57.9)$ & $15(40.5)$ & $11(47.8)$ \\
\hline \multicolumn{6}{|l|}{ Body mass index $\left(\mathrm{kg} / \mathrm{m}^{2}\right)$} \\
\hline$<25$ Underweight and normal weight & $1685(58.0)$ & $127(74.3)^{* *}$ & $39(68.4)^{*}$ & $30(81.1)^{* *}$ & $17(73.9)^{*}$ \\
\hline 25-30 Overweight & $839(28.9)$ & $27(15.8)$ & $9(15.8)$ & $4(10.8)$ & $3(13.0)$ \\
\hline$>30$ Obesity & $379(13.1)$ & $17(9.9)$ & $9(15.8)$ & $3(8.1)$ & $3(13.0)$ \\
\hline \multicolumn{6}{|l|}{ Hazard work exposure during pregnancy } \\
\hline No & $1034(35.6)$ & $55(32.2)$ & $21(36.8)$ & $13(35.1)$ & $5(21.7)$ \\
\hline Yes & 1869 (64.4) & $116(67.8)$ & $36(63.2)$ & $24(64.9)$ & $18(78.3)$ \\
\hline \multicolumn{6}{|l|}{ Maternal chronic diseases } \\
\hline No & $2208(76.1)$ & $125(73.1)$ & $35(61.4)^{* *}$ & $29(78.4)$ & $14(60.9)^{*}$ \\
\hline Yes & $695(23.9)$ & $46(26.9)$ & $22(38.6)$ & $8(21.6)$ & $9(39.1)$ \\
\hline \multicolumn{6}{|l|}{ Maternal stress } \\
\hline No & $2048(70.5)$ & $122(71.3)$ & $35(61.4)$ & $27(81.8)$ & $15(65.2)$ \\
\hline Yes & $855(29.5)$ & $49(28.7)$ & 22 (38.6) & $6(18.2)$ & $8(34.8)$ \\
\hline \multicolumn{6}{|l|}{ Infant sex } \\
\hline Male & $1469(50.6)$ & $91(53.2)$ & $29(50.9)$ & $13(35.1)^{*}$ & $17(73.9)^{* *}$ \\
\hline Female & 1434 (49.4) & $80(46.8)$ & $28(49.1)$ & $24(64.9)$ & $6(26.1)$ \\
\hline \multicolumn{6}{|l|}{ Socioeconomic status } \\
\hline Low & $854(30.6)$ & $52(31.7)$ & $18(34.6)$ & $12(34.3)$ & $10(43.5)$ \\
\hline Medium & $1516(54.2)$ & 78 (47.6) & $26(50.0)$ & $16(45.7)$ & $9(39.1)$ \\
\hline High & $425(15.2)$ & $34(20.7)$ & $8(15.4)$ & $7(20.0)$ & $4(17.4)$ \\
\hline \multicolumn{6}{|l|}{ Parity } \\
\hline No child & $2795(96.3)$ & $164(95.9)^{*}$ & $52(91.2)$ & $35(94.6)^{\star}$ & $23(100)$ \\
\hline$\geq 1$ child & $108(3.7)$ & $7(4.1)$ & $5(8.8)$ & $2(5.4)$ & 0 \\
\hline \multicolumn{6}{|l|}{ Previous preterm } \\
\hline No & $2630(90.6)$ & $147(86.0)^{* *}$ & $50(87.7)$ & $33(89.2)$ & $18(78.3)^{* *}$ \\
\hline Yes & $273(9.4)$ & $24(14.0)$ & 7 (12.3) & $4(10.8)$ & $5(21.7)$ \\
\hline \multicolumn{6}{|l|}{ Water filters } \\
\hline Yes & $878(30.2)$ & $53(31.0)$ & $14(24.6)$ & $13(35.1)$ & $7(30.4)$ \\
\hline No & $2025(69.8)$ & $118(69.0)$ & $43(75.4)$ & $24(64.9)$ & $16(69.6)$ \\
\hline Water supply area & & & & & \\
\hline Other & $1578(54.4)$ & $68(39.8)$ & $20(35.1)$ & 19 (51.4) & $5(21.7)^{\star *}$ \\
\hline Petrasiunai & $1325(45.6)$ & $103(60.2)$ & $37(64.9)$ & $18(48.6)$ & $18(78.3)$ \\
\hline
\end{tabular}


Table 2 Continued

\begin{tabular}{|c|c|c|c|c|c|}
\hline Risk factors & $\begin{array}{l}\text { Non-anomaly } \\
\text { n (\%) }\end{array}$ & $\begin{array}{l}\text { Any anomaly } \\
\mathrm{n}(\%)\end{array}$ & $\begin{array}{l}\text { Heart } \\
n(\%)\end{array}$ & $\begin{array}{l}\text { Musculoskeletal } \\
\text { n (\%) }\end{array}$ & $\begin{array}{l}\text { Urogenital } \\
\mathrm{n}(\%)\end{array}$ \\
\hline \multicolumn{6}{|c|}{ Trihalomethane internal dose } \\
\hline 1st tertile & $966(33.3)$ & $50(29.2)$ & $16(28.1)$ & $14(37.8)$ & $4(17.4)$ \\
\hline 2nd tertile & $987(34.0)$ & $59(34.5)$ & 18 (31.6) & $13(35.1)$ & $9(39.1)$ \\
\hline 3rd tertile & $950(32.7)$ & $62(36.3)$ & $23(40.4)$ & $10(27.0)$ & $10(43.5)$ \\
\hline
\end{tabular}

high THM exposure compared with women with low THM exposure.

\section{Association between THM internal dose during pregnancy and risk of congenital anomalies}

Using first-trimester daily THM uptake as both a continuous variable and categorised into tertiles, we examined the association between the internal THM dose and the risk of congenital heart anomalies (table 3).

Effect estimates based on TTHM and $\mathrm{CH}$ tertiles were slightly elevated for the exposure categories of the second and third tertiles compared with the first tertile, for the first trimester of pregnancy and for different trimester months. We found no statistically significant trends across the three exposure categories for TTHM and $\mathrm{CH}$. When analysed as continuous variables, TTHM and $\mathrm{CH}$ were associated with slightly elevated, but statistically non-significant, increases in the risk of congenital heart anomalies. However, we found dose-response relationships for the internal BDCM dose during the first month of pregnancy and the risk of congenital heart anomalies. The adjusted ORs of the second and third tertiles versus the first tertile were $1.87,95 \%$ CI 0.90 to 3.88 and $2.16,95 \%$ CI 1.05 to 4.46 , respectively $\left(\chi^{2}\right.$ for linear trend $\left.5.18, \mathrm{p}=0.024\right)$. The risk of congenital heart anomalies was associated with continuous BDCM exposure levels. The OR for every $0.1 \mu \mathrm{g} / \mathrm{d}$ increase in the BDCM internal dose in the first month of pregnancy was $1.77,95 \%$ CI 1.13 to 2.78 , and in the first trimester, it was $1.70,95 \%$ CI 1.09 to 2.66 . We also observed statistically significant excess risk for every $0.01 \mu \mathrm{g} / \mathrm{d}$ increase in the DBCM internal dose during the first month of pregnancy (OR 1.26, 95\% CI 1.01 to 1.58$)$ and in the first trimester of pregnancy (OR $1.25,95 \%$ CI 1.01 to 1.54 ).

Table 3 Adjusted ORs and $95 \%$ Cls for congenital heart anomalies by tertiles of internal THM exposure during the first trimester of pregnancy

\begin{tabular}{|c|c|c|c|c|c|c|c|c|}
\hline $\begin{array}{l}\text { THM internal dose tertile } \\
\text { limits }(\mu \mathrm{g} / \mathrm{d})\end{array}$ & $\mathbf{n}$ & $\begin{array}{l}\text { First month } 0 R^{*}(95 \% \\
\mathrm{Cl})\end{array}$ & $\mathbf{n}$ & $\begin{array}{l}\text { Second month OR* } \\
(95 \% \mathrm{Cl})\end{array}$ & $\mathbf{n}$ & Third month $\mathrm{OR}^{*}(95 \% \mathrm{Cl})$ & $\mathbf{n}$ & $\begin{array}{l}\text { First trimester } \mathrm{OR}^{*} \\
(95 \% \mathrm{Cl})\end{array}$ \\
\hline \multicolumn{9}{|l|}{ TTHM } \\
\hline $0.031-0.040$ & 16 & 1 & 15 & 1 & 18 & 1 & 16 & 1 \\
\hline $0.040-0.356$ & 17 & 0.94 (0.47 to 1.88 ) & 19 & 1.15 (0.58 to 2.28$)$ & 17 & 0.85 (0.43 to 1.67$)$ & 18 & 1.05 (0.53 to 2.07$)$ \\
\hline $0.356-2.448$ & 24 & 1.44 (0.76 to 2.74 ) & 23 & $1.50(0.78$ to 2.91 & 22 & 1.17 (0.62 to 2.12 ) & 23 & 1.38 (0.72 to 2.64$)$ \\
\hline $\mathrm{p} \dagger$ & & 0.162 & & 0.158 & & 0.450 & & 0.237 \\
\hline Continuous $(1 \mu \mathrm{g} / \mathrm{d})$ & & 1.96 (1.01 to 3.80$)$ & & 1.90 (0.98 to 3.70$)$ & & 1.72 (0.87 to 3.39$)$ & & 1.88 (0.96 to 3.69$)$ \\
\hline \multicolumn{9}{|l|}{ Chloroform } \\
\hline $0.001-0.026$ & 17 & 1 & 17 & 1 & 16 & 1 & 16 & 1 \\
\hline $0.026-0.288$ & 16 & 0.83 (0.41 to 1.65$)$ & 17 & 0.88 (0.45 to 1.75$)$ & 19 & 1.06 (0.54 to 2.08$)$ & 18 & 1.05 (0.53 to 2.08$)$ \\
\hline $0.288-2.109$ & 24 & 1.36 (0.72 to 2.56$)$ & 23 & 1.31 (0.70 to 2.49 ) & 22 & 1.34 (0.69 to 2.57 ) & 23 & 1.37 (0.72 to 2.63$)$ \\
\hline $\mathrm{p} \dagger$ & & 0.225 & & 0.283 & & 0.279 & & 0.245 \\
\hline Continuous $(1 \mu \mathrm{g} / \mathrm{d})$ & & 2.07 (0.96 to 4.46$)$ & & 2.01 (0.92 to 4.38 ) & & 1.79 (0.80 to 3.99$)$ & & 1.97 (0.90 to 4.35$)$ \\
\hline \multicolumn{9}{|l|}{$\mathrm{BDCM}$} \\
\hline $0.000-0.013$ & 11 & 1 & 14 & 1 & 16 & 1 & 12 & 1 \\
\hline $0.013-0.051$ & 22 & 1.87 (0.90 to 3.88 ) & 21 & 1.40 (0.71 to 2.78 ) & 20 & 1.19 (0.61 to 2.31$)$ & 22 & 1.74 (0.85 to 3.54$)$ \\
\hline $0.051-0.436$ & 24 & 2.16 (1.05 to 4.46$)$ & 22 & 1.54 (0.78 to 3.04 ) & 21 & 1.32 (0.68 to 2.56 ) & 23 & 1.82 (0.89 to 3.69 ) \\
\hline $\mathrm{p} t$ & & 0.024 & & 0.144 & & 0.309 & & 0.070 \\
\hline Continuous $(0.1 \mu \mathrm{g} / \mathrm{d})$ & & 1.77 (1.13 to 2.78$)$ & & 1.69 (1.09 to 2.62 ) & & 1.59 (1.02 to 2.46$)$ & & 1.70 (1.09 to 2.66 ) \\
\hline \multicolumn{9}{|l|}{$\mathrm{DBCM}$} \\
\hline $0.000-0.002$ & 20 & 1 & 18 & 1 & 17 & 1 & 18 & \\
\hline $0.002-0.006$ & 21 & 0.96 (0.52 to 1.79$)$ & 22 & 1.17 (0.62 to 2.20$)$ & 22 & 1.24 (0.65 to 2.36$)$ & 14 & 0.73 (0.36 to 1.48$)$ \\
\hline $0.006-0.093$ & 16 & 0.71 (0.37 to 1.39 ) & 17 & 0.87 (0.45 to 1.71$)$ & 18 & 1.00 (0.51 to 1.97 ) & 25 & 1.35 (0.73 to 2.51$)$ \\
\hline $\mathrm{p} \dagger$ & & 0.398 & & 0.742 & & 1.000 & & 0.283 \\
\hline Continuous $(0.01 \mu \mathrm{g} / \mathrm{d})$ & & 1.26 (1.01 to 1.58$)$ & & 1.24 (1.01 to 1.52$)$ & & 1.23 (1.00 to 1.50$)$ & & 1.25 (1.01 to 1.54$)$ \\
\hline
\end{tabular}

${ }^{*}$ Adjusted for: age, body mass index, chronic disease, alcohol consumption and fetus number.

$+\chi^{2}$ for linear trend.

BDCM, bromodichloromethane; DBCM, dibromochloromethane; THM, trihalomethane; TTHM, total trihalomethane. 
Table 4 Adjusted ORs and 95\% Cls for congenital musculoskeletal anomalies by tertiles of internal THM exposure during the first trimester of pregnancy

\begin{tabular}{|c|c|c|c|c|c|c|c|c|}
\hline THM internal dose tertile limits $(\mu \mathrm{g} / \mathrm{d})$ & $\mathbf{n}$ & $\begin{array}{l}\text { First month OR* } \\
(95 \% \mathrm{Cl})\end{array}$ & $\mathbf{n}$ & $\begin{array}{l}\text { Second month OR* } \\
(95 \% \mathrm{Cl})\end{array}$ & $\mathbf{n}$ & $\begin{array}{l}\text { Third month OR* } \\
(95 \% \mathrm{Cl})\end{array}$ & $\mathbf{n}$ & $\begin{array}{l}\text { First trimester } O \mathrm{R}^{*} \\
(95 \% \mathrm{Cl})\end{array}$ \\
\hline \multicolumn{9}{|l|}{ TTHM } \\
\hline $0.031-0.040$ & 14 & 1 & 14 & 1 & 14 & 1 & 14 & 1 \\
\hline $0.040-0.356$ & 14 & $0.92(0.43$ to 1.94$)$ & 14 & 0.91 (0.43 to 1.92$)$ & 15 & $0.99(0.47$ to 2.07$)$ & 13 & $0.90(0.42$ to 1.92$)$ \\
\hline $0.356-2.448$ & 9 & $0.63(0.27$ to 1.46$)$ & 9 & $0.63(0.27$ to 1.47$)$ & 8 & $0.57(0.24$ to 1.36$)$ & 10 & $0.69(0.31$ to 1.57$)$ \\
\hline pt & & 0.351 & & 0.357 & & 0.254 & & 0.446 \\
\hline Continuous $(1 \mu \mathrm{g} / \mathrm{d})$ & & $0.46(0.14$ to 1.52$)$ & & $0.54(0.17$ to 1.72$)$ & & 0.69 (0.23 to 2.04$)$ & & 0.55 (0.17 to 1.74$)$ \\
\hline \multicolumn{9}{|l|}{ Chloroform } \\
\hline $0.001-0.026$ & 16 & 1 & 16 & 1 & 14 & 1 & 17 & 1 \\
\hline $0.026-0.288$ & 12 & $0.71(0.33$ to 1.50$)$ & 12 & $0.69(0.33$ to 1.48$)$ & 15 & $0.98(0.47$ to 2.04$)$ & 11 & 0.61 (0.29 to 1.32$)$ \\
\hline $0.288-2.109$ & 9 & $0.56(0.25$ to 1.28$)$ & 9 & $0.56(0.25$ to 1.28$)$ & 8 & $0.57(0.24$ to 1.37$)$ & 9 & $0.51(0.22$ to 1.14$)$ \\
\hline pt & & 0.175 & & 0.180 & & 0.258 & & 0.111 \\
\hline Continuous $(1 \mu \mathrm{g} / \mathrm{d})$ & & 0.37 (0.09 to 1.48$)$ & & $0.43(0.11$ to 1.68$)$ & & 0.55 (0.15 to 2.03$)$ & & 0.43 (0.11 to 1.71$)$ \\
\hline \multicolumn{9}{|l|}{ BDCM } \\
\hline $0.000-0.013$ & 11 & 1 & 11 & 1 & 9 & 1 & 10 & 1 \\
\hline $0.013-0.051$ & 18 & 1.57 (0.73 to 3.35$)$ & 16 & 1.41 (0.65 to 3.06$)$ & 18 & 0.88 (0.36 to 2.19$)$ & 13 & 1.18 (0.51 to 2.71$)$ \\
\hline $0.051-0.436$ & 8 & 0.73 (0.29 to 1.84$)$ & 10 & $0.92(0.39$ to 2.17$)$ & 10 & $1.70(0.78$ to 3.71$)$ & 14 & 1.29 (0.57 to 2.92$)$ \\
\hline p† & & 0.639 & & 0.944 & & 0.708 & & 0.406 \\
\hline Continuous $(0.1 \mu \mathrm{g} / \mathrm{d})$ & & $0.79(0.33$ to 1.86$)$ & & $0.95(0.45$ to 2.00$)$ & & 1.15 (0.60 to 2.17$)$ & & 0.97 (0.46 to 2.06 ) \\
\hline \multicolumn{9}{|l|}{$\mathrm{DBCM}$} \\
\hline $0.000-0.002$ & 7 & 1 & 6 & 1 & 9 & 1 & 11 & 1 \\
\hline $0.002-0.006$ & 11 & 1.41 (0.54 to 3.65$)$ & 13 & 2.02 (0.76 to 5.36$)$ & 9 & $0.97(0.38$ to 2.45$)$ & 12 & 0.95 (0.42 to 2.18$)$ \\
\hline $0.006-0.093$ & 19 & 2.56 (1.07 to 6.13$)$ & 18 & 2.90 (1.14 to 7.35$)$ & 19 & 2.01 (0.90 to 4.48$)$ & 14 & $1.16(0.52$ to 2.57$)$ \\
\hline pt & & 0.024 & & 0.023 & & 0.061 & & 0.578 \\
\hline Continuous $(0.01 \mu \mathrm{g} / \mathrm{d})$ & & $1.18(0.86$ to 1.62$)$ & & $1.18(0.90$ to 1.56$)$ & & $1.20(0.94$ to 1.54$)$ & & $1.20(0.91$ to 1.58$)$ \\
\hline
\end{tabular}

*Adjusted for: body mass index, fetus number, previous premature birth and infant sex.

$\dagger \chi^{2}$ for linear trend.

BDCM, bromodichloromethane; DBCM, dibromochloromethane; THM, trihalomethane; TTHM, total trihalomethane.

There was little association between musculoskeletal anomalies and THM constituents (table 4).

The effect estimates showed a slight reduction of risk in the high tertiles of TTHM and CH exposure during the first trimester. Relative to the lowest tertile, we found an excess risk of musculoskeletal anomalies in the medium, but not the high, BDCM tertile during the first and second months of pregnancy. We consistently observed a slightly elevated, but statistically nonsignificant, increase in the musculoskeletal anomalies risk for the first trimester in the second and third BDCM exposure tertiles compared with the first tertile $(\mathrm{OR}=1.18$ and $\mathrm{OR}=1.29$, respectively). However, we found statistically significant trends in the association of DBCM exposure and musculoskeletal anomalies across the three exposure categories during the first month of pregnancy (vs the lowest tertile, OR 1.41, 95\% CI 0.54 to 3.65 , and OR $2.56,95 \%$ CI 1.07 to 6.13 for the second and third tertiles, respectively; $\chi^{2}$ for linear trend 5.11, $\mathrm{p}=0.024)$. A similar pattern was observed for exposures during the second month of pregnancy (vs the lowest tertile, OR 2.02, $95 \%$ CI 0.76 to 5.36 , and OR $2.90,95 \%$ CI 1.14 to 7.35 , for the second and third tertiles, respectively; $\chi^{2}$ for linear trend $5.18, \mathrm{p}=0.023)$. In a model using continuous DBCM exposure levels during the first trimester of pregnancy, there was a statistically non-significant association with the risk of musculoskeletal anomalies (OR 1.20, 95\% CI 0.91 to 1.58 ).

Table 5 describes the adjusted OR for the association of urogenital anomalies with internal THM exposure during the first trimester of pregnancy. In general, TTHM and $\mathrm{CH}$ exposure in the first trimester of pregnancy doubled the risk of urogenital anomalies, although this finding was not statistically significant.
However, we found a statistically significant dose-response trend between urogenital anomalies and the three DBCM exposure categories during the first trimester (vs the lowest tertile, OR $1.65,95 \%$ CI 0.48 to 5.67 , and OR $2.87,95 \%$ CI 0.92 to 8.99 , for second and third tertiles, respectively; $\chi^{2}$ for linear trend 4.36, $\mathrm{p}=0.039$ ).

All analyses were adjusted for variables known to have an effect on the risk of specific congenital anomalies.

\section{DISCUSSION}

We conducted a prospective cohort study to examine the effects of the internal THM dose totalled over the first trimester of pregnancy, and separately for each of the first 3 months of pregnancy, on congenital anomalies. Our study estimated the internal dose using information on individual women's water use. Individual exposure showed similar associations with the risk of congenital anomalies, whether it was analysed as a continuous variable or categorised into tertiles. We found little indication of a dose-response relationship between exposure to TTHM and $\mathrm{CH}$ and congenital heart and urogenital anomalies. These results were similar to the results obtained when comparing exposure to TTHM of high and low-level sites, in which high exposure was associated with an increased risk of heart and urogenital anomalies. When analysed as continuous variables, TTHM and $\mathrm{CH}$ exposure in the first trimester of pregnancy showed slightly elevated, but statistically non-significant, increases in the risk of congenital heart, urogenital and musculoskeletal anomalies. The relationship was stronger for brominated THM. For the congenital heart anomalies, a dose-response relationship was evident for BDCM exposures in the first month of 
Table 5 Adjusted ORs and $95 \%$ Cls for congenital urogenital anomalies by tertiles of internal THM exposure during the first trimester of pregnancy

\begin{tabular}{|c|c|c|c|c|c|c|c|c|}
\hline $\begin{array}{l}\text { THM internal dose tertile } \\
\text { limits }(\mu \mathrm{g} / \mathrm{d})\end{array}$ & $\mathrm{n}$ & $\begin{array}{l}\text { First month } \mathrm{OR}^{*}(95 \% \\
\mathrm{Cl})\end{array}$ & $\mathbf{n}$ & $\begin{array}{l}\text { Second month } \mathrm{OR}^{*}(95 \% \\
\mathrm{Cl})\end{array}$ & n & $\begin{array}{l}\text { Third month OR* }(95 \% \\
\mathrm{Cl})\end{array}$ & $\mathrm{n}$ & $\begin{array}{l}\text { First trimester } \mathrm{OR}^{*}(95 \% \\
\mathrm{Cl})\end{array}$ \\
\hline \multicolumn{9}{|l|}{ TTHM } \\
\hline $0.031-0.040$ & 5 & 1 & 4 & 1 & 5 & 1 & 4 & 1 \\
\hline $0.040-0.356$ & 8 & 1.54 (0.50 to 4.77$)$ & 10 & 2.46 (0.77 to 7.93$)$ & 8 & 1.52 (0.49 to 4.71$)$ & 9 & 2.19 (0.67 to 7.18$)$ \\
\hline $0.356-2.448$ & 10 & 1.95 (0.66 to 5.76$)$ & 9 & 2.32 (0.71 to 7.62$)$ & 10 & 2.01 (0.68 to 5.96$)$ & 10 & 2.49 (0.77 to 8.03$)$ \\
\hline $\mathrm{p} \dagger$ & & 0.176 & & 0.174 & & 0.175 & & 0.115 \\
\hline Continuous $(1 \mu \mathrm{g} / \mathrm{d})$ & & 1.92 (0.69 to 5.33$)$ & & 1.99 (0.72 to 5.49$)$ & & 2.02 (0.74 to 5.50$)$ & & 2.00 (0.72 to 5.56$)$ \\
\hline \multicolumn{9}{|l|}{ Chloroform } \\
\hline $0.001-0.026$ & 4 & 1 & 4 & 1 & 4 & 1 & 4 & 1 \\
\hline $0.026-0.288$ & 10 & 2.31 (0.72 to 7.43 ) & 11 & 2.45 (0.77 to 7.76$)$ & 10 & 0.44 (0.13 to 1.44$)$ & 9 & 2.21 (0.67 to 7.23 ) \\
\hline $0.288-2.109$ & 9 & 2.20 (0.67 to 7.22$)$ & 8 & 2.02 (0.60 to 6.76$)$ & 9 & 1.01 (0.41 to 2.53$)$ & 10 & 2.50 (0.78 to 8.06$)$ \\
\hline $\mathrm{p} t$ & & 0.180 & & 0.273 & & 0.174 & & 0.118 \\
\hline Continuous $(1 \mu \mathrm{g} / \mathrm{d})$ & & 2.10 (0.65 to 6.74$)$ & & 2.21 (0.69 to 7.08$)$ & & 2.26 (0.71 to 7.20$)$ & & 2.22 (0.69 to 7.17 ) \\
\hline \multicolumn{9}{|l|}{$\mathrm{BDCM}$} \\
\hline $0.000-0.013$ & 4 & 1 & 6 & 1 & 6 & 1 & 4 & 1 \\
\hline $0.013-0.051$ & 10 & $2.40(0.75$ to 7.73$)$ & 6 & 0.90 (0.29 to 2.83$)$ & 6 & 0.91 (0.29 to 2.86$)$ & 7 & 1.65 (0.48 to 5.67$)$ \\
\hline $0.051-0.436$ & 9 & 2.27 (0.69 to 7.43 ) & 11 & 1.81 (0.66 to 4.96$)$ & 11 & 1.85 (0.68 to 5.07$)$ & 12 & 2.87 (0.92 to 8.99$)$ \\
\hline $\mathrm{p} \dagger$ & & 0.165 & & 0.165 & & 0.158 & & 0.039 \\
\hline Continuous $(0.1 \mu \mathrm{g} / \mathrm{d})$ & & 1.55 (0.70 to 3.40$)$ & & 1.56 (0.74 to 3.29$)$ & & 1.55 (0.76 to 3.20$)$ & & 1.57 (0.74 to 3.37 ) \\
\hline \multicolumn{9}{|l|}{ DBCM } \\
\hline $0.000-0.002$ & 7 & 1 & 7 & 1 & 6 & 1 & 6 & 1 \\
\hline $0.002-0.006$ & 7 & 0.89 (0.31 to 2.58$)$ & 8 & $1.08(0.39$ to 3.00$)$ & 9 & $1.42(0.50$ to 4.02$)$ & 6 & 0.92 (0.29 to 2.87 ) \\
\hline $0.006-0.093$ & 9 & $1.17(0.43$ to 3.16$)$ & 8 & $1.06(0.38$ to 2.96$)$ & 8 & $1.22(0.42$ to 3.56$)$ & 11 & $1.79(0.65$ to 4.90$)$ \\
\hline pt & & 0.700 & & 0.890 & & 0.670 & & 0.210 \\
\hline Continuous $(0.01 \mu \mathrm{g} / \mathrm{d})$ & & $1.17(0.78$ to 1.77$)$ & & $1.17(0.80$ to 1.71$)$ & & $1.17(0.82$ to 1.66$)$ & & 1.17 (0.80 to 1.72$)$ \\
\hline
\end{tabular}

*Adjusted for: age, body mass index, chronic disease, previous premature birth and infant sex.

$t \chi^{2}$ for linear trend.

BDCM, bromodichloromethane; DBCM, dibromochloromethane; THM, trihalomethane; TTHM, total trihalomethane.

pregnancy; $\chi^{2}$ test for trend $\mathrm{p}$ was 0.024 . ORs increased by $70 \%$ (OR $1.70,95 \%$ CI 1.06 to 2.66 ) for every $0.1 \mu \mathrm{g} / \mathrm{d}$ increase in the internal dose of BDCM and by $26 \%$ (OR 1.26 , $95 \%$ CI 1.01 to 1.54$)$ for every $0.01 \mu \mathrm{g} / \mathrm{d}$ increase in the internal dose of DBCM.

There were statistically significant dose-response trends across the DBCM exposure categories for musculoskeletal anomalies $(p=0.024)$; and across the BDCM exposure categories for urogenital anomalies $(p=0.039)$. In the present study, the internal dose studied as a continuous variable more often revealed statistically significant association than in categorical analysis unadjusted $\chi^{2}$ test for trend.

Etiologic studies suggest that major structural anomalies occur within the first trimester of pregnancy. We found that congenital anomalies were associated with the internal THM dose during the first trimester of pregnancy, particularly in the first 2 months of pregnancy. These results may be related to the limited variation of the month-specific internal THM dose. In our analyses, it was difficult to evaluate the independent effects of exposures by month because they were highly correlated.

Reconciling our results with previous findings is not straightforward because of substantial differences in THM levels, individual THM constituents in drinking water, measurement and classification of individual exposures, variation of exposure over the months of pregnancy and the extent of controlling for confounders. In addition, our sample did not capture stillbirths and pregnancy terminations due to congenital anomalies diagnosed prenatally.
The specific mechanisms for the effects of THM on the risk of birth anomalies remain unknown. There is evidence that the metabolism and toxicity of different DBP species varies. ${ }^{23}{ }^{24} \mathrm{In}$ general, the brominated DBPs are more genotoxic and carcinogenic than the chlorinated compounds, and iodinated DBPs are the most genotoxic. ${ }^{25}$ Several mechanisms for the effects of THM have been suggested, including genotoxicity, oxidative stress, disruption of folate metabolism, lowering of testosterone levels and disruption of the synthesis and/or secretion of placental syncytiotrophoblast-derived chorionic gonadotropin. ${ }^{26}$ Because the brominated THMs are structurally similar, and because there is evidence for common pathways of bioactivation, findings ${ }^{27}$ support the idea that glutathione (GSH) conjugation of tribromomethane may lead to the formation of DNA-reactive metabolites in the liver and, more likely, in the colons of rodents and humans.

Brominated THM is thought to present a greater health risk than $\mathrm{CH}$, primarily because of differences in their metabolism and toxicokinetics. ${ }^{28} 29$ In addition, BDCM can disrupt syncytiotrophoblast formation and inhibit chorionic gonadotrophin secretion in vitro. ${ }^{29}$ This finding implies that the placenta is a likely target of BDCM toxicity in humans; thus, BDCM may have teratogenic effects on the fetus. An alternative explanation is that THM may lead to birth defects via genetic damage to maternal gametes. ${ }^{30}$ This damage may result in chromosomal abnormalities, enzymatic malfunction and disruption of cellular membranes, all of which could influence the formation of anomalies. 
Only a few studies have investigated associations between BDCM levels in drinking water and congenital anomalies. A study in southeast England ${ }^{31}$ that examined the risk of hypospadias and exposure to THM through water consumption and use concluded that ingestion of more than $6 \mathrm{mg} / \mathrm{d}$ of BDCM was associated with the risk of hypospadias (OR 1.65, 95\% CI 1.02 to 2.69). A population-based Canadian study reported a statistically significant association between BDCM and neural tube defects, ${ }^{9}$ whereas a study in both Canada and the USA found a negative association with neural tube defects and cleft lip and palate. ${ }^{13}$ A study in England and Wales ${ }^{16}$ reported that high total brominated THM exposures in the first trimester of pregnancy were not associated with significant excess risk of congenital anomalies. An Australian study reported a statistically significant increased risk of any congenital anomalies (OR 1.22, $95 \%$ CI 1.01 to 1.48 ) and of cardiac anomalies (OR 1.62, 95\% CI 1.04 to 2.51) among women exposed to high levels of TTHM in drinking water with high proportions of brominated THM (on average, 92\%). ${ }^{32}$ These results are consistent with our data in which the highest risk for congenital anomalies comes from brominated THM. To our knowledge, no previous studies have shown an association between the internal THM dose during pregnancy and the risk of congenital heart anomalies.

The strengths of our study include the population-based cohort design, the assessment of THM exposure during pregnancy, and the control for the effects of residential mobility by restricting the study to women who did not change residence during their pregnancy. This study also used advanced methods to calculate individual internal THM exposure during pregnancy based on residential THM levels and water use behaviours. Each subject's exposure was estimated as a daily internal dose of the THM constituents $(\mu \mathrm{g} / \mathrm{d})$. Exposures were analysed using both continuous and categorical variables. An additional strength of our study is that pregnant women were prospectively followed, which permitted collection of self-reported data on potential confounding factors, decreased exposure misclassification errors, and improved identification of congenital anomalies.

We acknowledge several limitations in this study. We did not gather information on water usage habits during the first trimester of pregnancy. Instead, women were interviewed during the third pregnancy trimester before delivery, which may have affected the estimation of THM uptake and may have led to exposure classification errors. However, water consumption habits and unmeasured confounders were likely to vary independently of the three THM exposure categories, and should not confound the relationships we observed. Misclassification of congenital anomalies was unlikely in this prospective study, as the presence of major congenital anomalies is recorded in the birth register and generally considered reliable. A study of congenital heart defect diagnoses in the infant population of Kaunas revealed that, over 7 years, up to $93.9 \%$ of congenital heart anomalies were diagnosed in delivery units. ${ }^{33}$ We have no possibility of studying the diagnostics of non-syndromic forms of the kidney and urinary tract anomalies. However, the analysis of anomalies diagnosed before the infant was discharged from the hospital should not bias study results, as the completeness of reporting is unrelated to the exposure of interest. In addition, the classification of congenital anomalies in our study was independent of exposure assessment.

Due to the lack of information regarding the validity of the internal dose assessment models used in our study, it is possible that the effect estimates we observed may be biased because of non-differential misclassification of the internal dose.

Our study findings show that higher levels of the brominated THM internal dose during the first trimester of pregnancy may be associated with an increased risk of congenital heart and musculoskeletal anomalies. Recently reported DBP toxicity from samples of the Kaunas HIWATE programme sites revealed that the number of identified DBPs, the level of DBPs, the cytotoxic potency and the genotoxic potency were all greater for sites with 'high level' THM relative to 'low level' THM. ${ }^{34}$ There was a clear difference in the genotoxic responses of the Kaunas 'high level' versus 'low level' THM site samples. These data suggest that the results of our epidemiological study are consistent with results from analytical chemistry and in vitro toxicology studies. However, the association between the internal THM dose and the risk of congenital anomalies observed in our study may be due to DBPs that were not studied, or to other toxic water contaminants, or occurred by chance.

Further studies are required to clarify the association of individual THM internal doses and congenital anomalies. Our results are preliminary and need to be confirmed in a larger sample with more variability in THM concentrations and internal THM doses. Investigations of drinking water DBPs that integrate quantitative toxicological data with analytical chemistry and human epidemiologic data to look at gene-environment interactions are one possibility. Given the controversy surrounding the association of THM levels in drinking water and adverse pregnancy outcomes, especially regarding congenital anomalies, a precautionary approach to brominated THM exposure during pregnancy is justified.

Acknowledgements We acknowledge the contribution of the Clinics of Kaunas University of Medicine in the recording of pregnancy outcomes. We also thank Maria Kostopoulou-Karadanelli and Stuart W Krasner for THM analyses and consultations.

Contributors RG conceived and designed the study. VK and JB were involved in primary data collection and assisted with writing the manuscript. JV performed statistical analysis. MJN provided critical input into the manuscript and drafted the manuscript. All authors read and approved the final version.

Funding This work was supported in part by grant FP6-036224 from the European Commission

\section{Competing interests None.}

\section{Patient consent Obtained.}

Ethics approval The research protocol was approved by the Lithuanian Bioethics Committee and informed consent was obtained from all subjects.

Provenance and peer review Not commissioned; externally peer reviewed.

Open Access This is an Open Access article distributed in accordance with the Creative Commons Attribution Non Commercial (CC BY-NC 3.0) license, which permits others to distribute, remix, adapt, build upon this work non-commercially, and license their derivative works on different terms, provided the original work is properly cited and the use is non-commercial. See: http://creativecommons.org/ licenses/by-nc/3.0/

\section{REFERENCES}

1 Nieuwenhuijsen MJ, Toledano MB, Eaton NE, et al. Chlorination disinfection by-products in water and their association with adverse reproductive outcomes: a review. Occup Environ Med 2000;57:73-85.

2 Gevecker Graves C, Matanoski GM, Tarfdiff RG. Weight of evidence for an association between adverse reproductive and developmental effects and exposure to disinfection by-products: a critical review. Regul Toxicol Pharmacol 2001;34:103-24.

3 Bove F, Shim Y, Zeitz P. Drinking water contaminants and adverse pregnancy outcomes: a review. Environ Health Perspect 2002;110(Suppl. 1):61-74.

4 Nieuwenhuijsen MJ, Martinez D, Grellier J, et al. Chlorination disinfection by-products in drinking water and congenital anomalies: review and meta-analyses. Environ Health Perspect 2009;117:1486-93.

5 King WD, Dodds L, Armson BA, et al. Exposure assessment in epidemiologic studies of adverse pregnancy outcomes and disinfection byproducts. J Expo Anal Environ Epidemiol 2004;14:466-72. 
6 Tardiff RG, Carson ML, Ginevan ME. Updated weight of evidence for an association between adverse reproductive and developmental effects and exposure to disinfection by-products. Regul Toxicol Pharmacol 2006;45:185-205.

7 Yang CY, Xiao ZP, Ho SC, et al. Association between trihalomethane concentrations in drinking water and adverse pregnancy outcome in Taiwan. Environ Res 2007; 104:390-5.

8 Grellier J, Bennett J, Patelarou E, et al. Exposure to disinfection by-products, fetal growth, and prematurity: a systematic review and meta-analysis. Epidemiology 2010;21:300-13.

9 Dodds L, King WD. Relation between trihalomethane compounds and birth defects. Occup Environ Med 2001;58:443-6.

10 Hwang BF, Jaakkola JJ. Water chlorination and birth defects: a systematic review and meta-analysis. Arch Environ Health 2003;58:83-91.

11 Hwang BF, Magnus $\mathrm{P}$, Jaakkola JJ. Risk of specific birth defects in relation to chlorination and the amount of natural organic matter in the water supply. Am J Epidemiol 2002;156:374-82.

12 Källén BA, Robert E. Drinking water chlorination and delivery outcome- a registration-based study in Sweden. Reprod Toxicol 2000;303-9.

13 Shaw GM, Ranatunga D, Quach T, et al. Trihalomethane exposures from municipal water supplies and selected congenital malformations. Epidemiology 2003;14:191-9.

14 Cedergren $\mathrm{MI}$, Selbing AJ, Löfman 0 , et al. Chlorination byproducts and nitrate in drinking water and risk for congenital cardiac defects. Environ Res 2002;89:124-30

15 Hwang BF, Jaakkola JJ, Guo HR. Water disinfection by-products and the risk of specific birth defects: a population-based cross-sectional study in Taiwan. Environ Health 2008;7:23.

16 Nieuwenhuijsen MJ, Toledano MB, Bennett J, et al. Chlorination disinfection by-products and risk of congenital anomalies in England and Wales. Environ Health Perspect 2008;16:216-22.

17 Grazuleviciene R, Nieuwenhuijsen MJ, Vencloviene J, et al. Individual exposures to drinking water trihalomethanes, low birth weight and small for gestational age risk: a prospective Kaunas cohort study. Environ Health 2011;10:32.

18 Nikolaou A, Golfinopoulos S, Rizzo L, et al. Optimisation of analytical methods for the determination of DBPs: application to drinking waters from Greece and Italy. Desalination 2005:176:25-36.

19 Backer LC, Ashley DL, Bonin MA, et al. Household exposures to drinking water disinfection by-products: whole blood trihalomethane levels. J Expo Anal Environ Epidemiol 2000;10:321-6.

20 Lynberg M, Nuckols JR, Langlois $P$, et al. Assessing exposure to disinfection by-products in women of reproductive age living in Corpus Christi, Texas, and Cobb
County, Georgia: descriptive results and methods. Environ Health Perspectiv 2001;109:597-604.

21 Savitz DA, Singer PC, Herring $A H$, et al. Exposure to drinking water disinfection by-products and pregnancy loss. Am J Epidemiol 2006;164:1043-51.

22 Whitaker HJ, Nieuwenhuijsen MJ, Best NG. The relationship between water concentrations and individual uptake of chloroform: a simulation study. Environ Health Perspect 2003;111:688-94.

23 IPCS. Disinfectants and disinfectant by-products. Environmental Health Criteria 216. Geneva: WHO, 2000.

24 Hunter ES, Rogers EH, Blanton MR, et al. Bromochlorohaloacetic acids: effects on mouse embryos in vitro and QSAR considerations. Reprod Toxicol 2006;21:260-6.

25 Plewa MJ, Wagner ED, Muellner MG, et al. Comparative mammalian cell toxicity of N-DBPs and C-DBPs. In: Karanfil T, Krasner SW, Westerhoff P, Xie Y.eds. Disinfection by-products in drinking water: occurrence, formation, health effects, and control. WashingtonDC: American Chemical Society, 2008:36-50.

26 Nieuwenhuijsen MJ, Grellier J, Smith R, et al. The epidemiology and possible mechanisms of disinfection by-products in drinking water. Philos Transact $A$ Math, Phys Eng Sci 2009;367:4043-76.

27 Ross MK, Pegram RA. In vitro biotransformation and genotoxicity of the drinking water disinfection byproduct bromodichloromethane: DNA binding mediated by glutathione transferase theta 1-1. Toxicol App/ Pharmacol 2004;195:166-81.

28 Bielmeier SR, Murr AS, Best DS, et al. Effects of bromodichloromethane on ex vivo and in vitro luteal function and bromodichloromethane tissue dosimetry in the pregnant F344 rat. Toxicol In Vitro 2007;21:919-28.

29 Chen J, Thirkill TL, Lohstroh PN, et al. Bromodichloromethane inhibits human placental trophoblast differentiation. Toxicol Sci 2004;78:166-74

30 Mayeno AN, Yang RS, Reisfeld B. Biochemical reaction network modeling: predicting metabolism of organic chemical mixtures. Environ Sci Techno 2005:39:5363-71.

31 Iszatt N, Nieuwenhuijsen MJ, Nelson P, et al. Water consumption and use, trihalomethane exposure, and the risk of hypospadias. Pediatrics 2011;127:e389.

32 Chisholm K, Cook A, Bower C, et al. Risk of birth defects in Australian communities with high brominated disinfection by-product levels. Environ Health Perspect 2008;116:1267-73.

33 Dulskiene $\mathrm{V}$, Malinauskiene $\mathrm{V}$, Azaraviciene $\mathrm{A}$, et al. The incidence and diagnostics of congenital heart defects in Kaunas infant population during 1999-2005. Medicina (Kaunas) 2008;44:139-46.

34 Jeong $\mathrm{CH}$, Wagner ED, Siebert VR, et al. Occurrence and toxicity of disinfection byproducts in European drinking waters in relation with the HIWATE epidemiology study. Environ Sci Techno 2012:46:12120-8. 